\title{
Antiembolik Çorap Yönetiminde Hemşirelerin Rol ve Sorumlulukları: Antiembolik Çorap Bakım Protokolü
}

\author{
Elif Akyüz, ${ }^{1}$ (D) Zahide Tunçbilek ${ }^{2}$
}

${ }^{1}$ Kırıkkale Üniversitesi Sağlık Bilimleri Fakültesi, Hemşirelik Bölümü, Kırıkkale, Turkey

${ }^{2}$ Hacettepe Üniversitesi Hemşirelik Fakültesi, Ankara, Turkey

\begin{abstract}
Özet
Derin Ven Trombozunun önlenmesi için kullanılan mekanik koruyucu yöntemler arasında en sık kullanılan, kullanımı kolay ve maliyeti etkin yöntemlerden biri antiembolik çoraplardır. Antiembolik çorapların etkin olabilmesi için bireye uygun beden ölçüsünde çorabın seçilmesi, doğru yöntemle giydirilmesi, bakımı, değerlendirilmesi ve hastanın bilgilendirilmesi önemlidir. Ancak antiembolik çorapların kullanımına yönelik klinik ortamda birçok uygulama hatası yapılmaktadır. Son on yılda yapılan çalışmalarda özellikle antiembolik çorapların yanlış kullanımına, yanlış beden seçimine ve olumsuz hasta sonuçlarına değinilmektedir. Antiembolik çorap giyen hasaların bakımında hemşireler anahtar sağlık profesyonelleridir. Hekim tarafından antiembolik çorap giydirilme istemi verildiğinde hemşirelerin hastalarını çorapların giydirilmesi için uygun hasta olup olmadığı konusunda değerlendirme, beden ölçüsünü belirleme, çorabı giydirme ve doğru kullanımını sağlama sorumlulukları vardır. Literatürde hemşirelerin antiembolik çorapların kullanımı ve bakımı konusunda özel bir eğitim almadıkları için beden seçimleri ile ilgili sorun yaşadıkları, rol ve sorumlulukları konusunda yeterli bilgiye sahip olmadıkları, yanlış uygulama yaptıkları ve olumsuz hasta sonuçlarına değinilmektedir. Bu derlemede hemşireler için geliştirilen ve antiembolik çorapların doğru ve etkin kullanımı için yapılması gereken girişimleri içeren protokol adımlarından bahsedilecektir.
\end{abstract}

Anahtar sözcükler: Hemşirelik bakımı; hemşirenin rolü; kompresyon çorapları; venöz tromboz.

\section{Nurses Role and Responsibilities on Management of Antiembolism Stockings: Antiembolism Stocking Care Protocol}

\begin{abstract}
One of the most frequently used, easy-to-use and cost-effective methods of mechanical protection for deep vein thrombosis prevention is antiembolism stockings. In order for stockings to be effective, it is important for the individual to select the appropriate size of socks, to wear it with the correct method, to care, to evaluate and to inform the patient. However, many application errors are made in the clinical environment for the use of stockings. Studies conducted in the last decade have specifically addressed the misuse of stockings, wrong body selection and negative patient outcomes. Nurses are the key health professionals in the care of the patients suffering from stockings. When a physician is asked to wear a antiembolism stocking, the nurses are responsible for assessing whether the patient is suitable for wearing the stockings, determining the body size, putting on the stockings, and ensuring proper use. In the literature, nurses don't have any special training in the use and care of antiembolism stockings, so they have problems with body selection, lack sufficient knowledge about their roles and responsibilities, they are doing wrong, and the results of negative patients are mentioned. In this review, protocol steps will be introduced for nurses, including initiatives for correct and effective use of antiembolism stockings.
\end{abstract}

Keywords: Compression stockings; nursing care; nurse's role; venous thrombosis.

Cite this article as: Akyüz E, Tunçbilek Z. Nurses Role and Responsibilities on Management of Antiembolism Stockings: Antiembolism Stocking Care Protocol. Turk J Cardiovasc Nurs 2018;9(20):96-104.

İletişim (Correspondence): Dr. Elif Akyüz. Kırıkkale Üniversitesi Sağlık Bilimleri Fakültesi Hemşirelik Bölümü Sağlık Yerleşkesi Fabrikalar Mahallesi, Ibni-Sina caddesi, No: 12, 06490 Kırıkkale, Turkey

Telefon (Phone): +90 3183573738 E-Posta (E-mail): ebayrak78@gmail.com

Başvuru Tarihi (Submitted Date): 13.10.2018 Kabul Tarihi (Accepted Date): 03.01.2019 
D erin ven trombozu (DVT) önlenebilen ve ölüme yol açan uluslararası önemli bir sağlık sorunudur. ${ }^{[1,2]}$ DVT dünyada ölüm nedenleri arasında üçüncü sırada yer almakta olup genel hastane ölümlerinin $\% 10$ 'undan sorumludur. [3, 4] DVT'nin önlenmesi, tedavisinden çok daha etkilidir. DVT'nin önlenmesi için çeşitli yöntemler kullanılmaktadır. Bu yöntemler farmakolojik tedavi, mekanik koruyucu girişimler ve fiziksel yöntemlerdir. Bu yöntemlerin temel amacl, trombüs oluşumunu engellemek ve emboli gibi komplikasyonları azaltmaktır. ${ }^{[1,2,6]}$ İdeal korunma yöntemi güvenli, uygulanması ve izlemi kolay, maliyeti uygun, hastalar, hemşireler ve hekimler tarafından kabul edilebilir nitelikte olmalıdır. ${ }^{[2,7,8]}$ Mekanik koruyucu yöntemler arasında en sık kullanılan, kullanımı kolay ve maliyeti etkin yöntemlerden biri antiembolik çoraplardır (AEÇ). $[2,5,6,8]$

Antiembolik çoraplar, risk grubundaki hastaların tümü için kullanılabilmektedir. Bu çoraplar farklı uzunlukta (diz altı, diz üstü, uyluk uzunluğunda, bele kadar tam boy vb), farklı beden ölçüsünde bulunmaktadır. ${ }^{[7-10]}$ Uygulama alanlarında sıklıkla uyluk uzunluğundaki AEÇ'lar kullanılmaktadır. AEÇ'lar etkin ve doğru şekilde kullanıldığında, postoperatif dönemde olan hastalarda kan akım hızını artırmakta, venöz damar dilatasyonu ve intimal hasarı önlemekte, venöz kapakları ve dolaşımı desteklemekte ve koagülasyonu sağlayarak DVT görülme oranını önemli derecede azaltmaktadır. ${ }^{[10-17]}$

Antiembolik çorapların etkin olabilmesi için bireye uygun beden ölçüsünde çorabın seçilmesi gerekmektedir. AEÇ beden ölçüsünün seçimi kadar giyimi, bakımı ve değerlendirilmesi de önem taşımaktadır. ${ }^{[1,18,19]}$ Williams ve arkadaşlarının (1996) yaptıkları çalışmada hastalara AEÇ'ların doğru beden ölçüsünde ve doğru teknikle giydirildiğinde hastaların hiçbirinde sorun yaşanmadığı, cilt problemi gelişmediği, çorabın uylukta uygun şekilde tespit edildiği, kaymaların ve ciltte halka şeklindeki basınç izlerinin gözlenmediği belirlenmiştir. ${ }^{[20]}$ Geerts ve arkadaşları (2008) AEÇ'ların kullanımının ve tromboemboliyi önlemeye yönelik diğer yöntemlerin rutin klinik uygulamalarda etkin yapılamadığını belirtmişlerdir. ${ }^{[13]}$ Son on yılda yapılan çalışmalarda özellikle $A E C ̧ ' l a r ı n$ yanlış kullanımına, yanlış beden seçimine ve olumsuz hasta sonuçlarına değinilmektedir. ${ }^{[1,2,10,13]}$

Antiembolik çoraplar birçok komplikasyonu önlemeye yönelik kullanılsa da çorapların kullanımına yönelik de komplikasyonlar gelişebilmektedir. ${ }^{[9,21,22]} \mathrm{AEÇ'a} \mathrm{bağlı} \mathrm{komplikas-}$ yonlar daha çok çorapların uygun şekilde giydirilmemesi, yanlış beden ölçüsünde giydirilmesi, takibinin doğru şekilde yapılmaması, çorap giyen hastaların uzun süre oturması, çorabın katlanarak kıvrılması, kıvrılmaya ve bir alanda toplanmaya bağlı olarak özellikle ayak bileklerinde ve diz kenarlarında turnike etkisi oluşturması ve bu etkinin uzun sürmesi nedeniyle görülmektedir. Özellikle bacaklarda ödemi olan hastalarda komplikasyonlar daha belirgin olabilmektedir. Sıklıkla görülen komplikasyon basınç yarasıdır. $[10,15,23]$ Trombüs oluşumu, sinir hasarı ve doku kaybı AEÇ kullanımından kaynaklanan diğer komplikasyonlar arasında yer almaktadır. ${ }^{[7,18,23]}$ Yapılan çalışmalarda iki saatten altı saate kadar olan sürede çorap kullanımına bağlı basınç ülseri geliştiği belirtilmiştir. $\left.{ }^{[9,} 10,15\right]$ AEÇ'lar DVT önlenmesinde etkili bir yöntem olsa bile yanlış kullanıldıklarında ya da hastanın çorap kullanımına uyumu değerlendirilmediğinde zararlı etkileri gözlenebilmektedir. ${ }^{[24]}$

Kliniklerde AEÇ kullanımına ilişkin gözlemlerimiz, hemşirelerin AEÇ'ın kullanımı ve bakımı konusunda özel bir eğitim almadıkları, beden seçimlerinde, çorabı giydirme öncesi hastanın bilgilendirilmesinde, giydirme sırasında, giydirdikten sonra çorabın gün içerisinde değerlendirilmesinde, hastanın bacak cildinin değerlendirilmesinde ve bakımının sağlanmasında, taburculuk sonrası süreçlerde hastanın bilgilendirilmesinde sorun yaşadıkları, eksik ve yanlış uygulamalar yaptıkları yönündedir. Bu nedenle bu derleme-

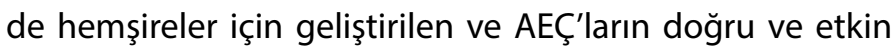
kullanımı için yapılması gereken girişimleri içeren protokol adımlarından bahsedilecektir.

\section{Antiembolik Çorap Yönetiminde Hemşirenin Rolü}

Antiembolik çorap giyen hasaların bakımında hemşireler anahtar sağlık profesyonelleridir. ${ }^{[10,12,15]}$ Hemşirelerin hastaları tromboemboliden koruyabilmek için koruyucu uygulamaları yapma sorumlulukları vardır. ${ }^{[10,25,26]}$ Hekim tarafından $\mathrm{AEÇ}$ giydirilme istemi verildiğinde hemşirelerin hastalarını AEÇ giydirilmesi için uygun hasta olup olmadığı konusunda değerlendirme, beden ölçüsünü belirleme, çorabı giydirme ve doğru kullanımını sağlama sorumlulukları vardır. ${ }^{[1,14,19,20,27]}$ Bu sorumluluklara yönelik $19 \mathrm{Ni}$ san 2011 tarihinde yayınlanan Hemşirelik Yönetmeliğinde Değişiklik Yapılmasına Dair Yönetmelikte yer alan çalışılan birim/servis/ünite/alanlara göre hemşirelerin görev, yetki ve sorumlulukları içerisinde hemşirenin "hastalarda emboli oluşumunu önleyici girişimleri bilir, hekimle birlikte gerekli planlamayı yapar ve uygular" ifadesi yer almaktadır. ${ }^{[26]} \mathrm{Ay}-$ rıca hemşireler, hasta ve ailesini DVT belirti ve bulguları, risk faktörleri, koruyucu önlemleri, yaşam şeklinde yapılabilecek düzenlemeleri, AEÇ'ın kullanım amacı ve kullanımında dikkat edilmesi gereken durumlar konusunda bilgilendirmesi gerekmektedir. ${ }^{[1,2,18,20]}$ Bu uygulamaları yapabilmesi için $A E C ̧ ' ı n$ kullanımı konusunda hemşirelere eğitim verilmesi gerekmektedir. ${ }^{[10,13,15]}$ Ayrıca AEÇ kullanımı konusunda bakım standardı geliştirilerek protokol veya reh- 
berlerin oluşturulmasına ihtiyaç duyulmaktadır. ${ }^{[10,18,23,28]}$ Klinik rehberler ile bakım protokolleri birbirleri yerine kullanılsa da ikisinin arasında önemli farklar bulunmaktadır. Hewitt-Taylor'un (2004) makalesinde rehber, eyleme yol gösteren ya da yönlendiren ilke ya da kriter; protokol ise bir prosedüre ilişkin kural olarak tanımlanmıştır. Protokoller tam olarak uyulması gereken eylemleri dikte ederken, rehberler daha az katı eylemleri önermektedir. ${ }^{[29]}$ Çalışmalarda hemşirelik bakım protokollerinin uygulamada hasta sonuçlarını olumlu yönde etkilediği gösterilmiştir. Knowles ve arkadaşlarının (2013) yaptıkları bir protokol çalışmasında, yoğun bakımda bağırsak yönetimine yönelik hemşireler ve sağlık personeli için oluşturulan protokol uygulamasının bağırsak yönetiminde olumlu etkilerinin olduğu, bu protokol uygulaması ile hemşirelerin daha önceki davranış, tutum ve inançlarına yönelik uygulamalarda önemli derecede düzelmelerin olduğu belirlenmiştir. ${ }^{[30]}$ Kaya ve ark. [31] (2016) Beyin Cerrahi Yoğun Bakım kliniğinde yaptıkları çalışmada hemşirelik bakım protokolü ile bakım vermenin santral venöz kateter ile ilişkili infeksiyonların önlenmesinde etkili olduğu bildirilmiştir. Bakım protokolü oluşturularak hemşirelik bakımının sunulması hasta sonuçlarına ve hemşirenin uygulama alanına fayda sağladığı görülmektedir. ${ }^{[30,31]}$ Ancak literatürde AEÇ kullanımına yönelik herhangi bir protokol bulunmamaktadır. Bu doğrultuda Akyüz
(2016) tarafından "Antiembolik Çorap Bakım Protokolü" geliştirilmiştir. ${ }^{[32]}$

\section{Antiembolik Çorap Bakım Protokolü}

Antiembolik Çorap Bakım Protokolü, literatürde yer alan çalışmalar ve rehberler ${ }^{[1,2,9,10,15,18,20,21,23]}$ dikkate alınarak oluşturulmuş olup kapsam geçerliliği için üç (3) uzman görüşüne başvurulmuştur. Bakım protokolü, $A E C ̧$ giydirilmeden önce, giydirilmesi esnasında ve giydirildikten sonra uygulanması gereken adımları içermektedir. ${ }^{[32]}$

\section{Antiembolik çorap giydirilmeden önceki adımlar; (Şekil 1)}

- Antiembolik çorap giydirilme isteminin kontrol edilmesi.

Eğer hastanın DVT riski var ise, hastaya cerrahi bir girişim planlanıyor ise, uzun süre yatak istirahati durumu söz konusu ise ya da tıbbi durumuna yönelik hastanın $A E C ̧$ giymesi gerektiği düşünülüyor ise hastanın doktoru tarafından $A E C ̧$ giymesi durumu istem edilmelidir. AEÇ kullanılması konusunda doktor istemi olan hastanın değerlendirmesi primer bakım vericisi olan hemşire tarafından yapılmalı, çorap kullanmaması gereken kontrendikasyon durumlarını belirlemeli ve doktoru ile iletişime geçerek $\mathrm{AEÇ} \mathrm{kullanma} \mathrm{duru-}$ munu gözden geçirmelidir. ${ }^{[10,22,28,32]}$

- Cildin değerlendirilmesi

Antiembolik çorap giydirilmeden önce hastanın cildi de-

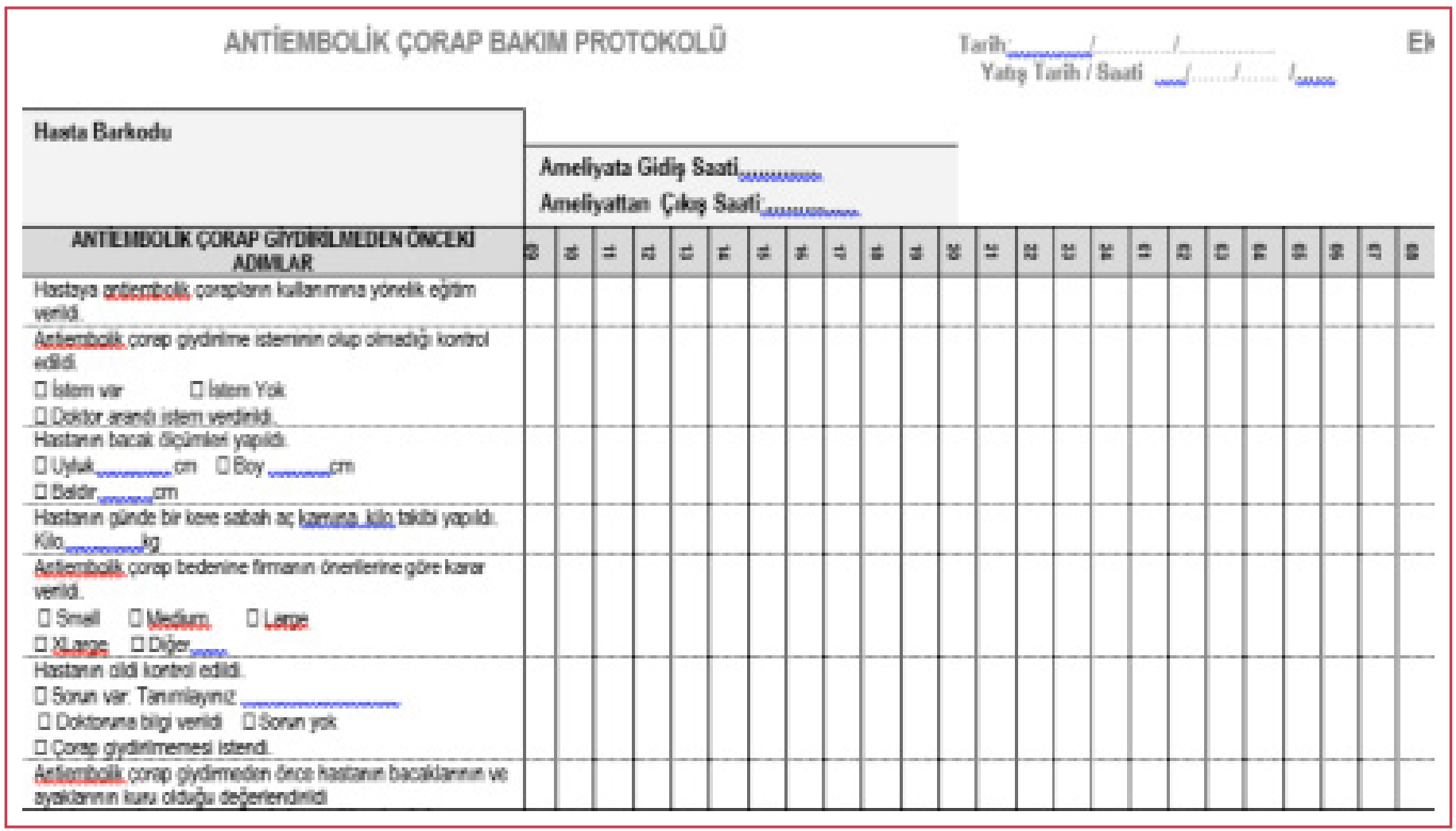

Şekil 1. AEÇ bakım protokolü antiembolik çorap giydirilmeden önceki adımlara ilişkin örnek. ${ }^{[32]}$ 
ğerlendirilmelidir. Cilt değerlendirilmesinde özellikle AEÇ giydirilmemesi gereken durumların varlığı dikkatlice incelenmelidir. AEÇ giydirmeden önce dolaşımın değerlendirilebilmesi için nörovasküler değerlendirme yapılmalıdır. Hastanın cildine ve dolaşımına yönelik yapılan değerlendirme kayıt altına alınmalıdır. $\left.{ }^{[9,} 10,15\right]$

\section{Antiembolik Çorap Kulanılmaması Gereken Durumlar}

- Aşırı bacak ödemi, pulmoner ödem, ödeme sekonder konjestif kalp yetersizliği

- Gangrenöz bacaklar

- Deri greft varlığı

- Açık deri lezyonları

- Arterioskleroz

- Çoklu periferal nöropati

- Periferal iskemik vasküler hastalık

- Bacakta dermatit ve geniş çapta deformite varlığı

- Bacakta selülit varlığı

Eğer hastada bu gibi durumların bir tanesinin varlığı söz konusu ise hemşire bu durumu rapor etmeli ve hastanın doktoruna bildirmelidir. ${ }^{[12,9,22]}$

Klinik rehberlere göre, $\mathrm{AEÇ} \mathrm{giydirilmeden} \mathrm{önce} \mathrm{bacaklar} \mathrm{ve}$ ayaklar kuru olmalıdır. Bu nedenle bu doğrultuda bacaklar ve ayaklar değerlendirilmelidir. ${ }^{[9,22]}$

- Hastanın bilgilendirilmesi

Antiembolik çorapların etkin kullanımını arttırmak için çorap giymeden önce, giydirme sırasında ve sonrası süreçlerde aralıklı olarak hasta ve ailesinin bilgilendirilmesi önemlidir. Bu bilgilendirme hemşireler tarafından yapılması gerekmektedir. ${ }^{[10,14,15,33]}$ Özkan ve ark. (2016) yaptıkları çalışmada hastaların en çok $A E C ̧ ' ı$ tek başına giyemedikleri ve çorabın terlettiği konusunda olumsuz görüş bildirdikleri belirlenmiştir. Bu çalışmada ayrıca, hastalar tarafından cilt kontrollerini yapmama (\%82.7), çorabın katlanmasına özen göstermeme (\%48), AEÇ üzerine çorap giyme (\%6.6), yırtık AEÇ'ı kullanma (\%1.3), çorabın topuk kısmını doğru yerleştirememe (\%1.3) gibi yanlış uygulamaların yapıldığı belirtilmiştir. Bu sonuçlar doğrultusunda sağlık profesyonelleri tarafından hastanın eğitilmesi, çorabın doğru giydiriliş şeklinin gösterilmesi, eğer hasta tarafından çorap doğru şekilde giyilmiyor ise çorap giyerken ve kullanırken hastaların gözlenmesi ve yanlış uygulamaların düzeltilmesi önerilmiştir. ${ }^{[34]}$

Hemşireler hastalarına AEÇ ile ilgili şu başlıklar altında bilgilendirme yapması gerekmektedir. ${ }^{[15,35]}$

- Antiembolik çorap giymek neden gereklidir?

- Antiembolik çorabın işlevi ve avantajları nelerdir?
- Antiembolik çorap nasıl giyilir?

- Ne zaman giyilir ve giydikten sonra nasıl bir bakım gerektirir?

- Hastanın dikkat etmesi gereken durumlar nelerdir?

- Antiembolik çoraba bağlı gelişebilecek komplikasyonlar nelerdir?

- Ne kadar süre ara verilebilir?

Ayrıca, antiembolik çorap giydirdikten sonra hastalara çorabı çevirmemeleri, kıvırmamaları, katlamamaları, büzüştürme, çekiştirme yapmamaları, çorabı çıkartmamaları, herhangi bir problem (kızarıklık, kaşıntı ve ağrı) yaşadıklarında hemşireye haber vermeleri konusunda bilgilendirme yapılmalıdır. ${ }^{[15,35]}$

- Hastanın bacak ölçümlerinin yapılması (Şekil 2)

Doğru ölçüm tekniği ile doğru beden ölçüsünün seçimi etkili sonuçların gelişmesini ve komplikasyonların önlenmesini sağlar. ${ }^{[10,15]}$ Antiembolik çorabın beden seçiminin doğru yapılabilmesi için üreticinin önerileri doğrultusunda uygun şekilde bacak ölçümleri yapılmalı ve uygulanmalıdır. Bacak ölçümleri ve karar verilen çorap bedeni hastanın daha sonraki bacak ölçümler ile karşılaştırmak ve çorabın uygun bedende olup olmadığını değerlendirebilmek için kayıt edilmelidir. Çorap hasta için çok küçük ise kesinlikle kullanılmamalıdır. Çünkü bu çorap hastanın bacaklarında turnike etkisi yaparak dolaşıma engel olacaktır. Çok büyük çoraplar da kullanılmamalı, çünkü bacaklarda yeterli desteği sağlamayacaktır. Çorapların ödeme bağlı oluşabilecek ve aşırı basıncına maruz kalmaya neden olabilecek komplikasyonlardan kaçınmak için bacak ölçümleri düzenli aralıklarla değerlendirilmeli ve yenilenmelidir. $[10,14,15,28,36]$

\section{Bacak Ölçümlerinde Dikkat Edilmesi Gereken Konular;}

- Çorabın bedenine karar verebilmek için her bir bacak için ölçme bandı (mezura) kullanılmalıdır.

- Bacak ölçümleri kullanılacak olan çorap üreticisinin önerileri doğrultusunda yapılmalıdır. Bazı firmalar hastanın bacak ölçümlerini baldırın ve uyluğun en geniş alanı ile bacak boyunun uzunluğunun (gluteal çizgiden topuk

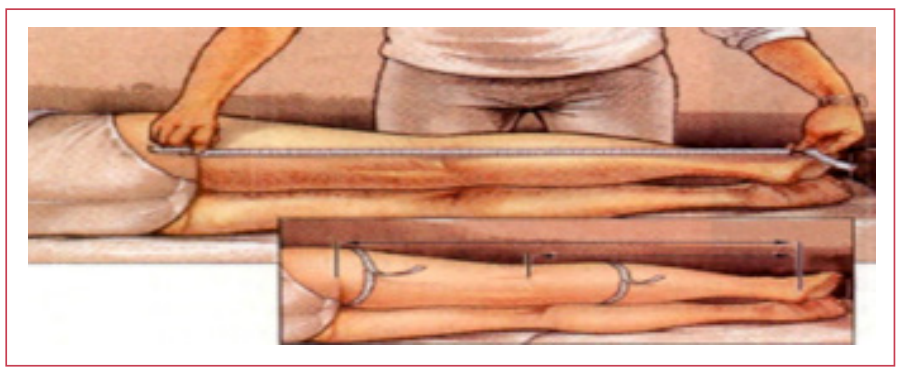

Şekil 2. Bacak ölçüm yöntemi. ${ }^{[18]}$ 
tabanına kadar) ölçülmesini isterken, bazı üreticiler ise ayak bileği ve uyluğun en geniş kısmının ölçülmesini isteyebilmektedir.

- Ölçümleri doğru şekilde yapabilmek için hastanın uzanması gerekmektedir.

- Yapılan bacak ölçümleri üreticinin ölçüm özellikleri ile karşılaştırılmalı ve çorap bedenine karar verilmelidir.

- Hastanede yatan hastalarda uzun süreli kullanımlarda eğer hastanın kilo aldığı veya verdiği düşünülüyor ise ölçümün tekrar edilmesi gerekmektedir. Ayrıca hastanın bacaklarında ödem geliştiği tespit ediliyor ise bacak ölçümleri yenilenmesi gerekmektedir. Ödeme bağlı bacak çevresindeki beş santimetrelik bir artış çorap tarafından uygulanan basıncı iki katına artırabilir.

- Hastanın her iki bacağı ödeme bağıı birbirinden farklı olduğu düşünülüyor ise bacak ölçümleri doğrultusunda iki bacağa farkı beden giydirilmesi gerekebilmektedir. $[10,14,15,28,36]$

\section{Antiembolik çorap giydirilmesi ile ilgili adımlar; (Şekil 3)}

Antiembolik çorap giydirilmeden önce hastanın bacaklarının dinlendirilmesi önemlidir. Hasta eğer çorap giydirilmeden önce yürümüş ise venöz geri dönüşü sağlayabilmek için 30 dakika önerilmekle birlikte en az 15 dakika bacaklar bel hizasına getirilecek şekilde ya da hastanın uzanması sağlanarak bacakların dinlendirilmesi gerekmektedir. Antiembolik çoraplar hastalara oturur pozisyonda giydirilmemelidir. $^{[10,15,18,37]}$

\section{- Antiembolik çorabın hazırlanması (Şekil 4)}

Antiembolik çorabın hastaya giydirilmeden önce hazırlanması gerekmektedir. Çorabı hazırlayacak olan kişi elini çorabın içine sokarak topuk cebine kadar (topuk kısmının merkezine kadar) ilerlemeli, topuk cebini kavrayarak çorabı topuk şeritinden hizalayarak geri kalan kısmı dışarı gelecek şekilde içinden dışına çorabı çevirmelidir. Daha sonra elini çoraptan çıkarmalıdır. Bu uygulama ile çorap giydirilmek üzere hazır hale getirilmiş olur. Bu yöntem kullanılarak antiembolik çorabın giydirilme işlemi daha kolay yapılabilmektedir. $[9,10,18,37]$

- Antiembolik çorabın giydirilmesi (Şekil 5)

Birey için uygun bedende çorabın seçimi kadar giyimi ve bakımı/değerlendirilmesi de oldukça önem taşımaktadır.

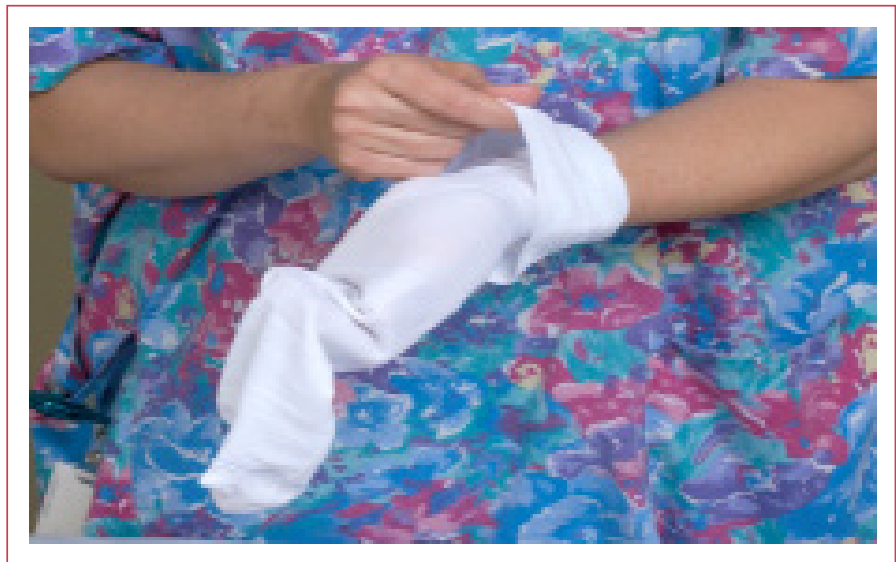

Şekil 4. Antiembolik çorabın hazırlanması. ${ }^{[37]}$

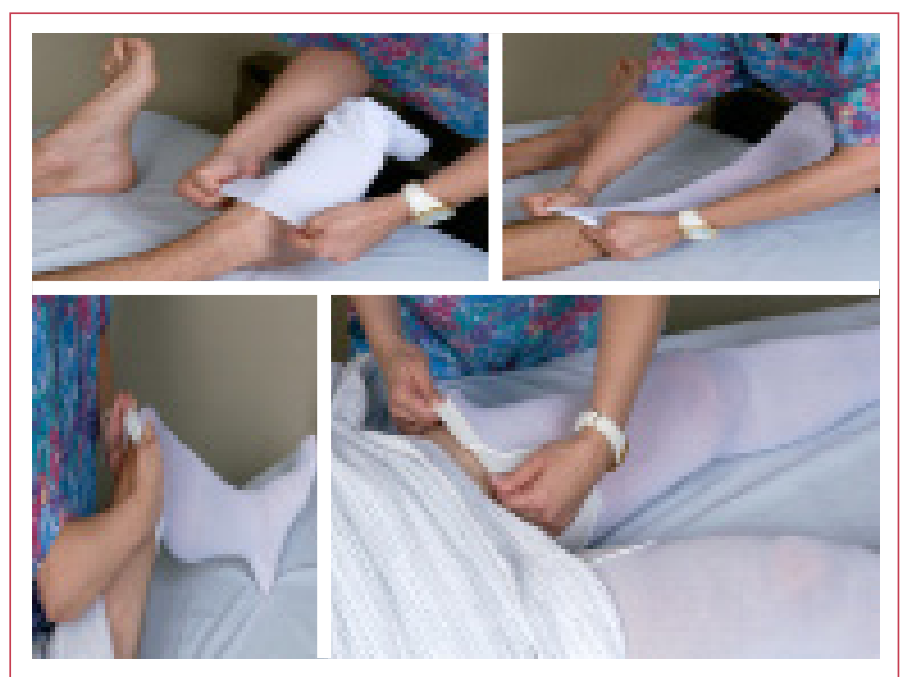

Şekil 5. Antiembolik çorabın giydirilme yöntemi. ${ }^{[37]}$

Literatürdeki bazı kaynaklar cerrahi hastalar için antiembolik çorap giydirilmesi için uygun zamanın ameliyattan en az iki saat önce olduğunu ve hasta tamamen mobil oluncaya kadar giymesi gerektiğini önermiştir. ${ }^{[9,10]}$ Antiembolik çorap giydirilirken aşağıdaki adımlara dikkat edilmelidir.

- Antiembolik çorap giydirmeden önce bacaklara herhangi bir merhem sürülmemelidir.

- Hastanın bacaklarının kuru olduğundan emin olunmalıdır. Eğer gerekli ise, hastanın pudraya karşı alerjisi yok ise az miktarda pudra kullanılabilir. Böylece çorap daha rahat bir şekilde giydirilebilir.

\begin{tabular}{|c|c|c|c|c|c|c|c|c|c|c|c|c|c|c|c|c|c|c|c|c|c|c|c|c|}
\hline 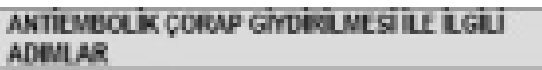 & $\mathrm{E}$ & s & $=$ & 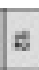 & $=$ & $=$ & \# & * & $\Rightarrow$ & 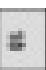 & 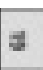 & 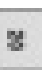 & $\approx$ & $\approx$ & $\approx$ & $z$ & $=$ & $\mathrm{s}$ & $=$ & $=$ & $=$ & 2 & $\Rightarrow$ & $=$ \\
\hline \multicolumn{25}{|l|}{ Crane hastand } \\
\hline 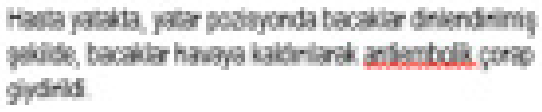 & & & & & & & & & & & & & & & & & & & & & & & & \\
\hline
\end{tabular}

Şekil 3. AEÇ bakım protokolü antiembolik çorap giydirilmesi ile ilgili adımlara ilişkin örnek. ${ }^{[32]}$ 
- Daha önceden hazırlanan çorabın ayak bölümü hastanın ayak parmaklarından geçirilerek topuk cebine çorabın topuk kısmı yerleştirilerek çorap ayak tabanına giydirilir. Daha sonra hastanın ayak bileğine kadar çekilir. Önce çorabın ayağı nasıl kavradığı kontrol edilir. Çorap ayak parmaklarını gevşek bir şekilde örtmelidir. Çorabın ayak bölümünü kendi etrafında çevirerek ya da ileri geri çekerek düzeltilmelidir.

- Çorabın geri kalan kısmı alınarak baldırı saracak şekilde çorap dize ve uyluğa kadar çekilmeli ve tüm bacak boyunu kavrayacak şekilde yukarı çekerek giydirilmelidir.

- Çorabın herhangi bir bölümünden kıvrılmadığından ve çorabın tepede toplanmadığından emin olunmalıdır. ${ }^{[9,}$ $10,15,18,22]$

- Uyluk uzunluğundaki çoraplar için hastanın femoral arter üzerine denk gelen silikon bant gluteal çizginin 2.5$7.5 \mathrm{~cm}$ aşağısına kadar uzanmalıdır.

- Hastaya çorap giydikten sonra herhangi bir alanda katlanma, kıvrılma olup olmadığından, çorabın uylukta doğru yerleştirildiğinden emin olunmalıdır.

- En son hastaya çorabın konforlu olup olmadığı sorulmalıdır. ${ }^{[10,33]}$ Bakker ve diğerlerinin (2013) yaptıkları

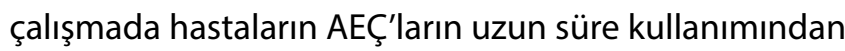
rahatsız oldukları yönünde gözlem yaptıkları bildirilmiştir. $^{[33]}$

\section{Antiembolik çorabın bakımı ve değerlendirilmesi ile il- gili adımlar; (Şekil 6)}

- Antiembolik çorabın uygun aralıklarla kontrol edilmesi

Klinik rehberlere göre hemşireler, çorabın doğru bedende olduğundan, doğru yerleştiğinden emin olabilmek ve herhangi bir alanda perfüzyonu engelleyecek bir kısıtlama, sıkma, katlanma ve birikme olmadığını belirlemek için çorabı düzenli olarak değerlendirmelidir. Hasta oturur pozisyonda olduğu sürelerde de hastanın çorapları herhangi bir alanda dolaşıma engel olabilecek katlanma, birikme, bilekte ve dizlerde turnike etkisi olup olmadığı değerlendirilmelidir. ${ }^{[9,}$ $10,14,15,28,36]$

\begin{tabular}{|c|c|c|c|c|c|c|c|c|c|c|c|c|c|c|c|c|c|c|c|c|c|c|c|c|}
\hline 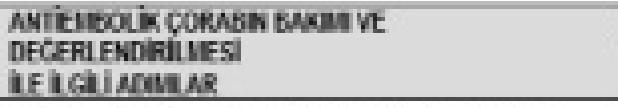 & e & $\mathbf{a}$ & $=$ & a & a & $z$ & $a$ & $\mathrm{z}$ & द & I & $a$ & $a$ & $=$ & $\mathrm{a}$ & a & 2 & $=$ & a & ta & $\mathbf{z}$ & i & E & e & $a$ \\
\hline 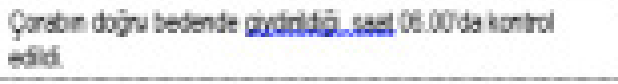 & & & & & & & & & & & & & & & & & & & & & & & & \\
\hline 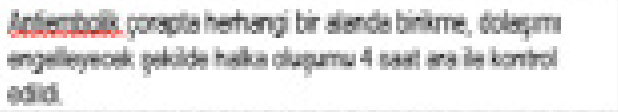 & & & & & & & & & & & & & & & & & & & & & & & & \\
\hline 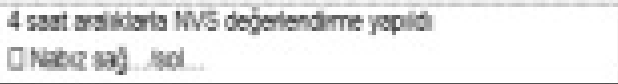 & & & & & & & & & & & & & & & & & & & & & & & & \\
\hline 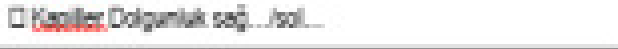 & & & & & & & & & & & & & & & & & & & & & & & & \\
\hline 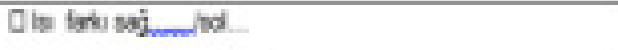 & & & & & & & & & & & & & & & & & & & & & & & & \\
\hline 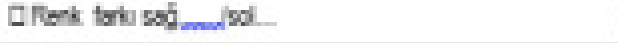 & & & & & & & & & & & & & & & & & & & & & & & & \\
\hline 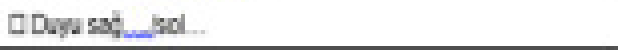 & & & & & & & & & & & & & & & & & & & & & & & & \\
\hline DHanded Milkal. & & & & & & & & & & & & & & & & & & & & & & & & \\
\hline 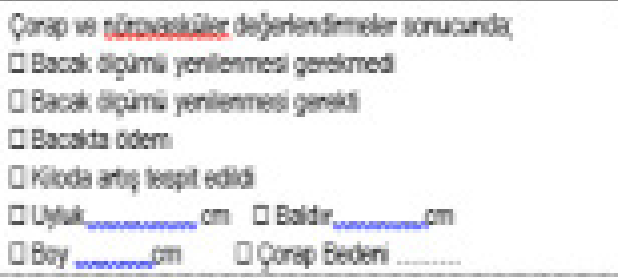 & & & & & & & & & & & & & & & & & & & & & & & & \\
\hline 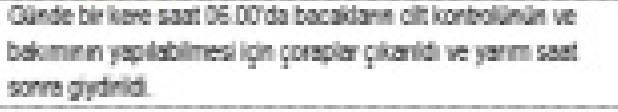 & & & & & & & & & & & & & & & & & & & & & & & & \\
\hline 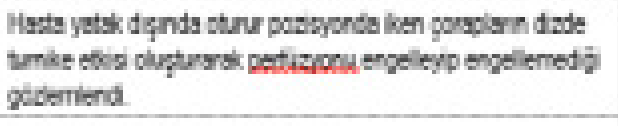 & & & & & & & & & & & & & & & & & & & & & & & & \\
\hline 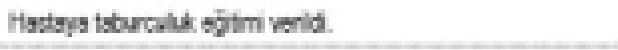 & & & & & & & & & & & & & & & & & & & & & & & & \\
\hline 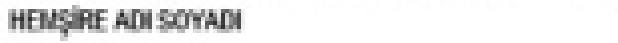 & & & & & & & & & & & & & & & & & & & & & & & & \\
\hline
\end{tabular}

Şekil 6. AEÇ bakım protokolü antiembolik çorabın bakımı ve değerlendirilmesi ile ilgili adımlara ilişkin örnek. ${ }^{[32]}$ 
- Nörovasküler değerlendirmenin yapılması

Çorap çıkartıldığında cilt bakımı sırasında, diğer zamanlarda ise çorabın ayak parmak alanındaki açıkıktan düzenli olarak her şiftte nörovasküler değerlendirme yapılmalıdır. $[10,14,15,28,36]$ Bu değerlendirme antiembolik çorabın dolaşım değerlendirme cebinden de yapılabilmektedir. AEÇ giydirildikten yarım/bir saat sonra hemşireler bacakta kapiller dolgunluğu, renk değişikliğini, duyu, hareket ve ısı farkını kontrol etmeli ve kayıt etmelidir. Bu kontrol çorabın etkin kullanılıp kullanılmadığının değerlendirilmesini sağlar. ${ }^{[14]}$ Aynı zamanda yarım/bir saat sonraki değerlendirmede çoraba bağlı gelişebilecek alerjik reaksiyon konusunda değerlendirmenin yapılması, kızarıklığın, kaşıntının, perfüzyonda bozulmanın ve doku hasarının gözlenmesi önerilmektedir. Eğer hastada ödem mevcut ise literatürde sekiz saatlik araIıklarla yapılacak olan değerlendirmenin mümkün ise dört saat aralıklarla değerlendirilmesi önerilmektedir. ${ }^{[10,14,15]}$

- Çorabın çıkartılması ve cildin değerlendirilmesi

Antiembolik çoraplar kullanırken cilt bakımı oldukça önemlidir. Cildi değerlendirebilmek ve cilt bakımını sağlayabilmek için günde en az bir kere çorap çıkartılmalıdır. ${ }^{[10,} 14$, $15,28,36]$ Hastanın bacak cildinin daha sık değerlendirilmesi gerekliliği söz konusu ise bu çorap daha sık çıkartılarak değerlendirme yapılmalıdı. ${ }^{[9,10,37]}$

Cilt bütünlüğü; ciltte lezyon, kızarıklık, nem, sıcaklık, renk değişikliği, ödem ve şişlik yönünden değerlendirilir. Bu değerlendirmenin hemşireler tarafından her şift, en az sekiz saatte bir, günde bir ya da iki kere çorap çıkartılarak yapılması şeklinde literatürde öneriler ve yapılan çalışmalar mevcuttur. $^{[10,15]}$ Sigel ve arkadaşları (1975), sağlıklı bireylerde hareketsizlik sırasında bacakların venöz sistemindeki basıncın femoral ven akım hızına bağlı olduğuna değinmiştir. Bu durumun antiembolik çorapların bireyden çıkarıldıktan sonra 30 dakika için sürdürüldüğü belirtilmiştir. Bu nedenle çalışmalarında antiembolik çorapların yatan hareketsiz bireylerden 30 dakikadan daha uzun süre çıkarılmaması gerektiğini gösteren klinik bir kanıt olarak savunmuşlardır. [38]

Antiembolik çoraba bağıı hastanın bacak cildinde herhangi bir alerjik reaksiyon, kabarma, cilt renginde değiş̧iklik, tromboflebit, kızarıklık ya da ağı gelişirse, antiembolik çorap kullanılmamalı ve alternatif olabilecek mekanik profilaktik yöntem kullanılması tercih edilmelidir. Antiembolik çoraba bağlı gelişen bu yan etkiler mutlaka kayıt edilmelidir. ${ }^{[14,37]}$

- Hastaya taburculuk eğitiminin verilmesi

Bakımın önemli noktalarından biri de hasta eğitimidir. Çorabın hangi amaçla kullanıldığı, doğru beden seçimi, çorabın giydirilmesi, cildin değerlendirilmesi, korunması ve bacakların ödem yönünden değerlendirilmesinin gerekliliği konularında hastalara eğitim verilmelidir. ${ }^{[10, ~ 14, ~ 15, ~ 28, ~ 36] ~}$

Yapılan birçok çalışma göstermiştir ki hastalar antiembolik çorap kullanımına yönelik istendik düzeyde bilgiye sahip değiller. Özellikle taburculuk sonrası çorabı ne kadar süre kullanacakları ve nasıl bir bakım sağlayacakları yönünde bilgi eksikliği mevcuttur. Bunun en büyük sebebi ise hastalara gerekli eğitimin hemşire tarafından verilmemesi ya da sözel olarak verdiği eğitimin hastanın anlaması ve akılda kalma konusunda yeterli olmamasıdır. Yazılı olarak broşür verilmemesi bir diğer etken olabilir. ${ }^{[10,15,35]}$

Antiembolik çorap giymeden önce ve giydirilmesi sırasında hastalara ve hasta yakınlarına, antiembolik çorap kullanım amacı, çorap giymeden önce bacakların dinlendirilmesi, cilt ve bacakların dolaşımının değerlendirilmesi, çorap bedenine karar verme, bacak ölçümü yapma, çorap giyme yöntemi ve antiembolik çorap kullanırken dikkat etmesi gereken durumlar konusunda hemşire tarafından bilgi verilmesi gerekmektedir. ${ }^{[10,35,39]}$ Bu bilgiler hastaya sağlandıktan ve hasta tarafından anladığı değerlendirildikten sonra taburculuk eğitiminde bu bilgilere ek olarak aşağıda yer alan başlıklar doğrultusunda da hasta bilgilendirilmelidir.

- Antiembolik çorap kullanmaya devam edecek mi?

- Antiembolik çorabı ne kadar süre kullanacak?

- Antiembolik çorap kullanmaya ne sıklıkla ne kadar süre ara verebilecek?

- Antiembolik çorap kullanırken dikkat etmesi gereken durumlar nelerdir?

- Cilt değerlendirmesini ve bakımını nasıl yapacak? Cilt değerlendirmesinde nelere dikkat etmesi gerekecek?

- Antiembolik çorap nasıl yıkanacak?

- Antiembolik çorap bedeni hangi şartlarda değişmesi gerekecek?

- Hangi durumlarda çorap kullanmayı bırakacak?

- Hangi durumlarda doktora/hemşireye başvurması gerekecek? $^{[10,18,35,39]}$

Hastaya, mobilizasyonu istendik düzeyde olmadığı sürece antiembolik çorabı gece ve gündüz kullanması gerektiği açıklanmalıdır. ${ }^{[15,23]}$ Hemşire hastasına antiembolik çorap kullanım süresince çoraba bağlı herhangi bir ağrı, basınç hissi, yara, sıyrık, lezyon, ayak parmaklarında renk bozukluğu, parmaklarda soğukluk, ayaklarda karıncalanma ve iğne batması, bacakta ödem vb. cilt değişiklikleri yönünden cildini değerlendirmesi gerektiğini söylemelidir. Hastalara bu gibi durumların herhangi birisinin gelişmesi durumunda çorap kullanmayı bırakması gerektiği belirtilmelidir. Aynı zamanda hastasını antiembolik çorabın özellikle diz kenarları, ayak bileği ve uyluk altında olmak üzere herhangi bir 
alanda katlanma ve kırışıklık yapıp yapmadığı konusunda dikkatli olması, oturur pozisyonda olduğu sürelerde bu alanlarda oluşacak kırışıklık ve katlanmaları düzeltmesi gerektiği konularında bilgilendirmelidir. Hastanın cilt bakımını antiembolik çorap kullanımına ara verdiği süre içerisinde yapabileceği bilgisi verilmelidir. ${ }^{[10,32,35]}$

Antiembolik çorapların ayda iki çift kullanılabileceği, kirlendikçe ya da rutin üç günde bir ılık sabunlu su ile yıkanarak düz bir zemine serilerek kurutulabileceği bilgisi verilmelidir. Ayrıca tercih edenler için çamaşır makinesinin düşük devirli programında ve ılık/soğuk su ayarında çorapların yıkanabileceği söylenmelidir. ${ }^{[23,35]}$

Hastalara antiembolik çorapların kendisi için uygun bedende olmadığını düşündürecek düzeyde bacak ödemi olduğunda, ya da çok fazla kullanımı nedeni ile elastikiyetini kaybettiğini düşündüğünde değiştirmesi gerektiği konusunda bilgi verilmelidir. Şiddetli bacak ödemi olduğunda, antiembolik çorap kullanımına bağı bacaklarda ağıı, kızarıklık, kaşıntı gibi alerjik reaksiyon geliştiğine dair bir bulguya rastlandığında, antiembolik çoraba bağı bacaklarında basınç yarası geliştiğinde doktora/hemşireye başvurabileceği iletilmelidir. ${ }^{[18]}$

\section{Sonuç ve Öneriler}

Birçok hasta grubunda kullanılmakla birlikte tüm cerrahi işlem geçirecek hastalara sıklıkla kullanılan antiembolik çorapların doğru kullanımı konusunda yanlış uygulamalar yapılmaktadır. Yapılan yanlış uygulamalar ise hastalarda komplikasyonlara sebep olmaktadır. Antiembolik çorapların doğru kullanımı konusunda ciddi bilgi eksikliği mevcuttur. Bu konuda hemşireler kendilerini yetersiz hissetmekte, yanlış uygulamalar yapmakta, ya da sorumluluğu olmadığını düşünerek hiçbir uygulama yapmamakta ve hastalara gerekli bilgilendirme yapılmamaktadır. Literatürde ise irdelenmesi gereken bir konu olarak değerlendirilmekle birlikte protokolü geliştirilerek bilginin standardize edilmesi önerilmektedir. Antiembolik çorap yönetiminde hemşireler anahtar sağlık profesyonelleridir. Hemşirelerin hastalarını AEÇ giydirilmesi için uygun hasta olup olmadığı konusunda değerlendirme, beden ölçüsünü belirleme, çorabı giydirme ve doğru kullanımını sağlama sorumlulukları vardır. Bu uygulamaları yapabilmesi için $A E C ̧ ' ı n$ kullanımı konusunda hemşirelere eğitim verilmesi gerekmektedir. Akyüz (2016) tarafından geliştirilen Antiembolik Çorap Bakım Protokolü'nün tüm hastanelerde kullanılması, bu konuda tüm hemşirelerin eğitilmesi, kurum prosedür ve talimatlarında yer alması önerilmektedir.
Hakem Değerlendirmesi: Dış bağımsız.

Çıkar Çatışması: Yazarlar arasında herhangi bir çıkar çatışması bulunmamaktadır.

Yazarlık Katkıları: Konsept: E.A., Z.T.; Dizayn: E.A., Z.T.; Veri Toplama veya İşleme: E.A., Z.T.; Analiz veya Yorumlama: E.A., Z.T.; Literatür Arama: E.A., Z.T.; Yazan: E.A., Z.T.

\section{Kaynaklar}

1. Sage SL, McGee M, Emed JD. Knowledge of venous thromboembolism (VTE) prevention among hospitalized patients. Journal of Vascular Nursing 2008;26:109-17. [CrossRef]

2. Autar R. A review of the evidence for the efficacy of anti-embolism stockings (AES) in venous tromboembolism (VTE) prevention. Journal of Orthopedic Nursing 2009;13:41-9. [CrossRef]

3. Altıntaş F. Thromboembolism in hip and knee arthroplasties. Acta Orthop et Traumato 2000;34:101-9.

4. Kurtoğlu M, Sivrikoz E. Deep vein thrombosis: diagnosis, treatment, prophylaxis [Article in Turkish]. Harran Üniversitesi Tıp Fakültesi Dergisi 2008;5:34-42.

5. Ryan K, Johnson S. Preventing DVT: A perioperative perspective. Journal of Perioperative Practice 2009;19:55-9. [CrossRef]

6. Büyükyılmaz F, Şendir M. A problem that is neglected in postoperative care: Diagnosis of deep vein thrombosis (DVT) and nursing care [Article in Turkish]. Erciyes Üniversitesi Sağlık Bilimleri Dergisi 2014;23:48-54.

7. Wells SP, Lensing AWA, Hirsh J. Graduated compression stockings in the prevention of postoperative venous thromboembolism. Arch Intern Med 1994;154:67-72. [CrossRef]

8. Dirimeşe E, Yavuz M. Prevention of venous thromboembolism in surgical clinics [Article in Turkish]. Maltepe Üniversitesi Hemşirelik Bilim ve Sanatı Dergisi 2010;2:98-105.

9. Joanna Briggs Institute. Graduated compression stockings fort he prevention of postoperative venous thromboembolism. Best Practice 2001;5:1-6.

10. Winslow HE, Brosz DL. Graduated compression stockings in hospitalized postoperative patients: correctness of usage and size. Am J Nurs 2008;108:40-50. [CrossRef]

11. Salman CM, Durukan B, Deren Ö, Durukan T. Thrombosis prophylaxis in gynecology [Article in Turkish]. Turkish Journal of Obstetrics and Gynecology 2005;2:31-6.

12. Morrison R. Venous thromboembolism: Scope of the problem and nurse's role in risk assessment and prevention. Journal of Vascular Nursing 2006;24:82-90. [CrossRef]

13. Geerts WH, Bergqvist D, Pineo G.F, Heit J.A, Samama CM, Lassen MR, et al. Prevention of venous tromboembolism: American Collage of Chest Physician evidence-based clinical practice guidelines. Chest 2008;133:381-453. [CrossRef]

14. Joanna Briggs Institute (JBI). Graduated compression stockings for the prevention of postoperative venous thromboembolism. Best Practice 2008;12:1-4.

15. Li MG, Yuan MT, Qi WG. Implementation of best practice evidence in the nursing management of graduated compression stockings in the prevention of venous thromboembolism in an adult surgical setting. Evidence in Action 2012;9:35-42. 
16. Kahn SR, Shapiro S, Wells SP, Rodger MA, Kovacs Mj, Anderson $\mathrm{DR}$, et al. Compression stockings to prevent post-thrombotic syndrome: a randomised placebo-controlled trial. The Lancet 2014;383:880-8. [CrossRef]

17. Rider BC, Coughlin AM, Hew-Butler TD, Goslin BR. Effect of compression stockings on physiological responses and running performance indivision III collegiate cross-country runners during a maximal treadmill test. J Strength Cond Res 2014;28:1732-8. [CrossRef]

18. McConnell E. Applying antiembolism stockings. Nursing: April 2002;32:17. [CrossRef]

19. Autar R. NICE guidelines on reducing the rrisk of venous thromboembolism (deep vein thrombosis and pulmonary embolism) in patients undergoing surgery. Journal of Orthopedic Nursing 2007;11:169-76. [CrossRef]

20. Williams AM, Davies PR, Sweetnam DI, Harper G, Pusey R, Lightowler CD. Knee-length versus thigh-length graduated compression stockings in the prevention of deep vein thrombosis. The British Journal of Surgery 1996;83:1553. [CrossRef]

21. Amaragiri SV, Lees TA. Elastic compression stockings for prevention of deep vein thrombosis. Cochrane Database of Systematic Reviews 2006;2:1-20.

22. Gee E. Anti-embolism stockings. Nursing Times 2011;107:18-19.

23. Philips SM, Gallagher M, Bucha, H. Use graduated compression stockings postoperatively to prevent deep vein thrombosis. Brit Med J 2008;336:943-4. [CrossRef]

24. Feist RW, Andrade D, Nass L. Problems with measuring compression device performance in preventing deep vein thrombosis. Thrombosis Research 2011;128:207-9. [CrossRef]

25. Dilks A, Green J, Brown S.. The use and benefits of compression stockings aid. Nursing Times 2005;101:32.

26. 19 Nisan 2011 Hemşirelik Yönetmeliğinde Değiş̧iklik Yapılmasına Dair Yönetmelik. Çalışılan birim/servis/ünite/alanlara göre hemşirelerin görev, yetki ve sorumlulukları (2011). T.C. Resmi Gazete, 27910, 19 Nisan 2011 Salı.

27. Wallis M, Autar R. Deep vein thrombosis: Clinical nursing management. Nursing Standards 2001;15:47-54. [CrossRef]

28. Hayes MJ, Lehman AC, Castonguay P. Graduated compression stockings: updating practice, improving compliance. Medical Surgical Nursing 2002;11:163-7.

29. Hewitt-Taylor J. Clinical guidelines and care protocols. Intensive and Critical Care Nursing 2004;20:45-52. [CrossRef]

30. Knowles S, Lam TL, Mclnnes E, Elliott D, Hardy J, Middleton S. Knowledge, attitudes, beliefs and behaviour intentions for three bowel management practices in intensive care: effects of a targeted protocol implementation for nursing and medical staff. BioMed Central Nursing 2013;14:1-13.

31. Kaya H, Turan Y, Akbal S, Tosun K, Aksoy E, Tunalı Y ve ark. The effect of nursing care protocol on the prevention of central venous catheter-related infections in neurosurgery intensive care unit. Appl Nurs Res 2016;32:257-61. [CrossRef]

32. Akyüz E. Development of antiembolism stocking care protocol and evaluation of efficacy. Doctoral thesis 2016. Hacettepe Üniversitesi, Sağlık Bilimleri Enstitüsü. Ankara.

33. Bakker NA, Schieven LW, Bruins RMG, Van Den Berg M, Hissink RJ. Compression stockings after endovenous laser ablation of the greatsaphenous vein: A prospective randomized controlled trial. Eur J Vasc Endovasc 2013;46:588-92. [CrossRef]

34. Özkan ZK, Fındık ÜY, Ünver S. Evaluation of patients using postoperative compression stockings [Article in Turkish]. Florance Nightingale Hemşirelik Dergisi 2016;24:30-7.

35. May V, Clarke T, Coullin, S, Cowie L, Cox R, Day D, et al. What information patients require on graduated compression stockings. British Journal of Nursing 2006:15:263-70. [CrossRef]

36. Munyisia NE, Yu P, Hailey D. The impact of an electronic nursing documentation system on efficiency of documentation by caregivers in a residential aged care facility. J Clin Nurs 2012;21:2940-8. [CrossRef]

37. Applying antiembolism stockings isn't just pulling on socks. Nursing: August 2004;34:48-9. [CrossRef]

38. Sigel B, Edelstein AL, Savitch L, Hasty JH, Felix WR. Type of compression for reducing venous stasis. A study of lower extremities during inactive recumbency. Arch Surg-Chicago 1975;110:171-5. [CrossRef]

39. Walker L, Lamont $S$. The use of antiembolic stockings. Part 1: a literature review. British Journal of Nursing 2007;16:1408-12. 